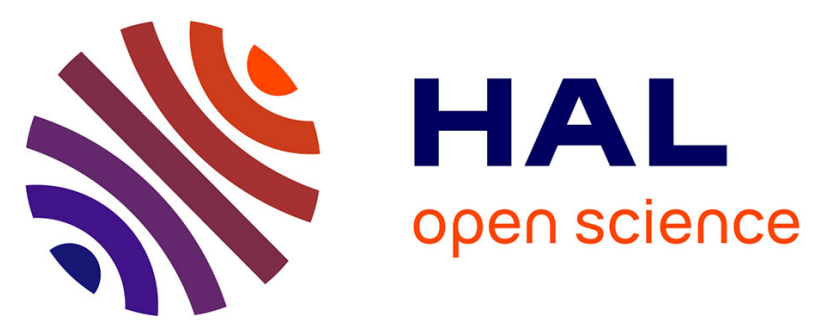

\title{
Influence of Environmental Factors on the Fate of Legacy and Emerging Per- and Polyfluoroalkyl Substances along the Salinity/Turbidity Gradient of a Macrotidal Estuary
}

Gabriel Munoz, Hélène Budzinski, Pierre Labadie

\section{- To cite this version:}

Gabriel Munoz, Hélène Budzinski, Pierre Labadie. Influence of Environmental Factors on the Fate of Legacy and Emerging Per- and Polyfluoroalkyl Substances along the Salinity/Turbidity Gradient of a Macrotidal Estuary. Environmental Science and Technology, 2017, 51 (21), pp.12347-12357. 10.1021/acs.est.7b03626 . hal-02060622

\section{HAL Id: hal-02060622 \\ https://hal.science/hal-02060622}

Submitted on 7 Mar 2019

HAL is a multi-disciplinary open access archive for the deposit and dissemination of scientific research documents, whether they are published or not. The documents may come from teaching and research institutions in France or abroad, or from public or private research centers.
L'archive ouverte pluridisciplinaire HAL, est destinée au dépôt et à la diffusion de documents scientifiques de niveau recherche, publiés ou non, émanant des établissements d'enseignement et de recherche français ou étrangers, des laboratoires publics ou privés. 
Influence of environmental factors on the fate of legacy and emerging per- and polyfluoroalkyl substances (PFASs) along the salinity/turbidity gradient of a macrotidal estuary

Gabriel Munoz ${ }^{\mathrm{a}}$, Hélène Budzinskib and Pierre Labadie ${ }^{\mathrm{b}, *}$

a: University of Bordeaux, UMR 5805 EPOC, LPTC Research Group, 33405 Talence, France.

b: CNRS, UMR 5805 EPOC, LPTC Research Group, 33405 Talence, France.

*Corresponding author. Contact: pierre.labadie@u-bordeaux.fr

DOI: 10.1021/acs.est.7b03626 


\section{Graphical abstract}

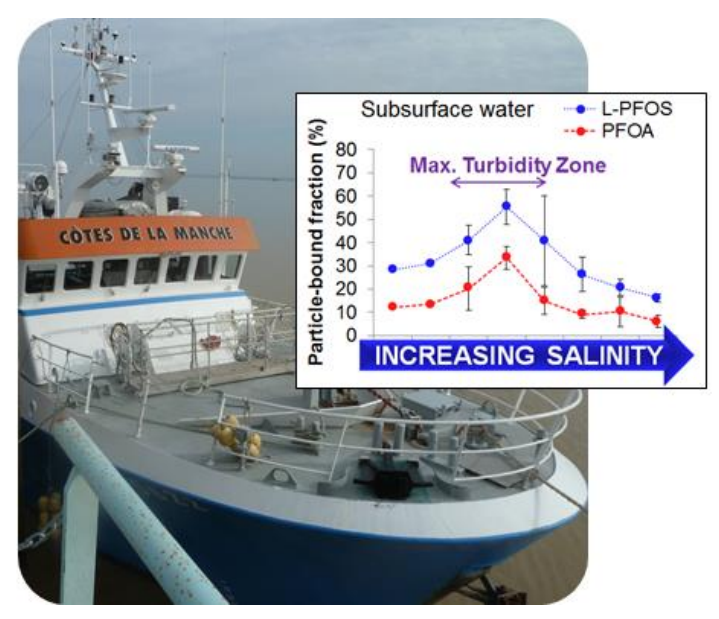




\section{Abstract}

This study aimed at bridging knowledge gaps regarding the land-sea transport of per- and polyfluoroalkyl substances (PFASs) through riverine discharge into coastal waters. The present survey was conducted in the Gironde estuary (southwestern France) where PFASs were ubiquitously detected albeit at low levels. Emerging PFASs such as fluorotelomer sulfonates or polyfluoroalkyl phosphate diesters accounted for a relatively minor proportion of ¿PFASs, while perfluorooctane sulfonate, perfluorohexane sulfonate, and perfluorohexanoate were the predominant congeners. Multiple linear regressions provided insights into the relative influence of factors controlling PFAS sediment levels. In that respect, the organic carbon fraction (strongly correlated to sediment grain size) appeared as a more important controlling factor than black carbon or distance from upstream sources for longchain perfluoroalkyl acids. In the maximum turbidity zone (suspended solids up to $2600 \mathrm{mg} \mathrm{L}$ $\left.{ }^{1}\right)$, the particle-associated fraction was almost consistently $>50 \%$ for long-chain perfluoroalkyl carboxylates and sulfonates ( $\geq \mathrm{C} 8$ and $\geq \mathrm{C} 6$, respectively). Empirical models of $K_{D}$ partitioning coefficients were derived by integrating, for the first time, both particleconcentration and salting-out effects. These results represent a significant progress toward the development of numerical transport models integrating both PFAS partitioning and 3Dhydrosedimentary dynamics, with a view to estimate PFAS mass budgets at the land-sea interface. 


\section{Introduction}

In the global context of anthropogenically-induced changes, the dissemination of persistent organic pollutants (POPs) in natural environments, which may pose threats to human health and wildlife, has emerged as a major issue in the last 60 years. While legacy POPs are still under close scrutiny of environmental monitoring programs, the past two decades have also witnessed the identification of POPs of emerging concern. Such is the case of perfluoroalkyl and polyfluoroalkyl substances (PFASs). PFASs are synthetic fluorosurfactants that have been produced since the 1950s and that have catered to requirements of industrial processes, consumer goods, and specialty applications including firefighting foam formulations. ${ }^{1-4}$ Despite early observations of perfluorooctanoate (PFOA) in workers from fluorochemical facilities or initial evidence of toxicity on mammals, it was not until 1999-2001 that the global extent of PFAS distribution in natural environments was established. ${ }^{5}$ Since then, PFASs have been recognized as pollutants of emerging concern. ${ }^{6}$ The environmental research on PFASs has been extensive, with a special focus on perfluoroalkyl acids (PFAAs), either used in the industry for decades or resulting from the degradation of numerous fluoroalkylated precursors. ${ }^{7-10}$ Long-chain PFAAs are of particular concern, being candidates for classification as very persistent and very bioaccumulative (vPvB); additionally, these compounds may biomagnify in food webs. ${ }^{11,12}$ In 2009, perfluorooctane sulfonate (PFOS) and related compounds were listed under Annex B of the Stockholm Convention on POPs. ${ }^{3}$ PFASs have been identified as ubiquitous contaminants, found even in remote areas such as the Amazonian rain forest, ${ }^{13}$ polar regions, ${ }^{14,15}$ and global oceans. ${ }^{16}$ Taken together, these findings provide evidence of potential for long-range transport (LRT) of these chemicals, which may occur via both atmospheric transport and global oceanic circulation. ${ }^{17,18}$

In contrast to many POPs, most PFASs are amphiphilic compounds; this implies that models traditionally used for POPs (e.g., relying on descriptors such as the octanol-water partitioning coefficient, $K_{o w}$ ) show limited reliability to predict the environmental fate of ionic PFASs. ${ }^{19}$ Thus, field or laboratory studies are still warranted to document the partitioning properties of PFASs after release. Sorption of PFAAs onto sediment or suspended particulate matter (SPM) has been shown to correlate with perfluoroalkyl chain length. ${ }^{20-22}$ Factors reported to influence the water-sediment distribution coefficient of PFASs include solution-specific parameters such as salinity, ${ }^{24-26}$ dissolved organic matter ${ }^{24}$ or $\mathrm{pH}^{27}$, and sorbent-specific properties such as grain-size, organic carbon content ${ }^{20,24,27-30}$, black carbon content, ${ }^{31}$ and total basicity or pore-size ${ }^{32}$. In transitional waters such as estuaries, wide fluctuations of such parameters may occur both temporally and spatially. ${ }^{33-35}$ Removal of contaminants from the water column may be enhanced at neap tides (low current velocities) as coarser particles 
settle on the bed sediment, while the resuspension of sediment by upcoming tides may contribute to their partial resupply through desorption or pore-water liberation. ${ }^{36,37}$ In addition, the sharp increase in salinity is expected to produce "salting-out" effects (decrease in aqueous solubility with increasing ionic strength). ${ }^{38,39}$

To date, the influence of physicochemical parameters on PFAS sorption has been principally investigated under controlled laboratory conditions. Typically fewer studies have sought to endorse the conclusions drawn through real in situ measurements at the land-sea interface. Hong et al. ${ }^{25}$ investigated the in situ partitioning of PFASs in their survey across multiple South Korea estuaries. By compiling the results obtained from different sites, the authors suggested that the $K_{D}$ coefficients could increase as a function of salinity, providing preliminary yet convincing evidence of some salting-out of long-chain PFAAs. ${ }^{25}$ This commendable effort to document salinity constants would appear as a first step toward modeling PFAS sedimentation or export. In order to further calibrate and validate numerical models of PFAS partitioning that are both spatially and temporally integrated, however, critical knowledge gaps remain to be bridged with regard to PFAS in situ partitioning. For instance, suspended particles can also play a significant role in estuarine biogeochemistry cycles (e.g. adsorption/desorption hysteresis of contaminants). ${ }^{33}$ To the authors' best knowledge, no previous study has examined the in situ influence of the suspended solids concentration on PFAS partitioning behavior. Hong et al. ${ }^{25}$ did not find a high correlation between $K_{D}$ and salinity, indicating that the latter parameter only partly explained the variability of the data, and that adding other variables could possibly improve the model. It may be hypothesized that both salinity and SPM load would exert a strong influence on the environmental fate of PFASs, which provided the grounds for the present study.

The Gironde estuary (SW France) constitutes a relevant study site to verify this assumption, with the ulterior aim of modeling the transport of PFASs from upstream riverine sources and sequestration within the estuary boundaries prior to oceanic export. The Gironde is a macrotidal highly turbid estuary characterized by a fairly permanent maximum turbidity zone (MTZ), typically extending several tens of kilometers. Due to these hydrogeological settings, it is feasible to undertake in this system a temporally and spatially integrated survey covering an extended range of salinity values and suspended solid loads. These aspects are determinant for the generation of statistically sound correlations between $K_{D}$ and controlling environmental factors. In addition, PFAS inputs to the estuary essentially originate from upstream sources (i.e. Toulouse and Bordeaux conurbations) and not from smaller tributaries in the estuarine area (data not shown). Such particular features provide a unique opportunity to investigate the environmental fate of PFASs through the salinity and turbidity gradient while minimizing confounding PFAS lateral inputs, which represented another powerful argument for the study site selection. The Gironde is also of great ecological significance. A 
variety of diadromous fish spend the juvenile part of their life cycle in its brackish waters, ${ }^{40,41}$ during which they may be particularly vulnerable to environmental pollutions; the trophic transfer of PFASs in this system was recently investigated. ${ }^{42}$

The overarching aim of the present study was to determine whether PFASs would be scavenged along the salinity/turbidity gradient of a macrotidal highly turbid estuary. This entailed the delineation of three specific objectives: (i) to document the spatial distribution of PFAS levels and profiles in subsurface and bottom water as well as in subtidal sediments and intertidal mudflats, (ii) to determine which physicochemical factors drive PFAS levels in the sediment, and (iii) to investigate PFAS environmental fate in the water column through the calculation of $\log K_{D}$ and $\log K_{O C}$ partitioning coefficients and modeling of the former by combining salting-out and particle-concentration effects. To this end, a large number of water samples (dissolved phase and SPM) $(n=84)$ and sediment samples $(n=34)$ were collected at large spatial scale in this estuary. The robustness of the empirical models generated for $K_{D}$ was finally examined by validation with an independent data set. The results from the present survey convey important implications for future modeling of the in situ fate and transport of PFASs at the continent-sea interface.

\section{Experimental}

\section{Chemicals}

A full list of chemicals and solvents is enclosed in the Supporting Information (SI). Certified PFAS native compounds $(n=27)$ and isotope-labeled internal standards (ISs) $(n=14)$ were all acquired from Wellington Laboratories (BCP Instruments, Irigny, France) (chemical purity $>98 \%$ and isotopic purity $>94 \%$ ). The native PFASs purchased included perfluoroalkyl carboxylates (PFCAs: PFBA, PFPeA, PFHxA, PFHpA, PFOA, PFNA, PFDA, PFUnDA, PFDoDA, PFTrDA, PFTeDA), perfluoroalkyl sulfonates (PFSAs: PFBS, PFHxS, PFHpS, PFOS and PFDS), perfluorooctane sulfonamide (FOSA) and its $\mathrm{N}$-alkylated derivatives (MeFOSA and EtFOSA), perfluorooctane sulfonamide acetic acids (MeFOSAA and EtFOSAA), polyfluoroalkyl sulfonates (FTSAs: 4:2 FTSA, 6:2 FTSA, and 8:2 FTSA), and polyfluoroalkyl phosphate diesters (diPAPs: 6:2 diPAP and 8:2 diPAP). In the case of PFOS branched isomers (Br-PFOS), the concentrations were calculated from the calibration curve used for L-PFOS. ${ }^{30}$ Note that, in this paper, the total of linear (L-PFOS) and branched (BrPFOS) isomers is referred as "PFOS". ${ }^{13} \mathrm{C}_{2}$-PFHxA, ${ }^{13} \mathrm{C}_{4}$-PFOA, ${ }^{13} \mathrm{C}_{2}$-PFDA, ${ }^{13} \mathrm{C}_{2}$-PFUnDA, ${ }^{13} \mathrm{C}_{2}$-PFDoDA, ${ }^{13} \mathrm{C}_{2}$-PFTeDA, ${ }^{18} \mathrm{O}_{2}$-PFHxS, ${ }^{13} \mathrm{C}_{4}$-PFOS, $\mathrm{D}_{3}$-N-MeFOSAA, ${ }^{13} \mathrm{C}_{8}-\mathrm{FOSA}, \mathrm{D}_{3}-\mathrm{N}-$ MeFOSA, D $D_{5}$ N-EtFOSA, ${ }^{13} \mathrm{C}_{2}-6: 2$ FTSA and ${ }^{13} \mathrm{C}_{4}-6: 2$ diPAP were used as ISs. Analyte 
name, acronym, structure and corresponding IS are provided in the SI (Tables S1 and S7S8).

\section{Study Site and Sampling Strategy}

The Gironde estuary originates at the junction of the Garonne and Dordogne rivers at Bec d'Ambès ( $1.6 \mathrm{~km}$ wide), widens gradually in a northwestward direction (> $10 \mathrm{~km}$ wide just before the mouth), and opens into the ocean near Le Verdon (SI Fig.S1). Flowing over nearly $80 \mathrm{~km}$ and covering approximately $625 \mathrm{~km}^{2}$ at high tide, the Gironde estuary is often described as the largest in Western Europe. The hydrology and geochemistry of the Gironde have been well-documented in earlier studies. ${ }^{43-47}$ The Gironde is a macrotidal estuary (tidal amplitude: $1.5-5 \mathrm{~m}$ at the mouth), with a MTZ (SPM > $1 \mathrm{~g} \mathrm{~L}^{-1}$ ) typically stretching over several tens of $\mathrm{km}$. Its estimated mean annual flow rate is $760 \mathrm{~m}^{3} \mathrm{~s}^{-1}$ and the residence time of water typically ranges between 1-3 months. Low- and moderate-flow periods prevail for a large part of the year and correspond to the MTZ being typically located in the central area of the estuary. The large spatial extent of the SPM and salinity gradient would make these conditions ideal to observe contrasted conditions within this estuary. The export of particulate material into the adjacent continental shelf occurs rather discontinuously, as a result of exceptional flood events. Hence, suspended particles remain typically between 1-2 years within the MTZ. ${ }^{48}$ Historical metallic contamination has been established in a series of studies, especially cadmium. ${ }^{49}$ To date, the occurrence of POPs in the Gironde estuary has only been documented in a few surveys. ${ }^{50,51}$

The HALOGIR sampling campaign took place in September $2014\left(3^{\text {rd }}-7^{\text {th }}\right)$ aboard the Côtes de la Manche research vessel. In order to account for potential transversal variations, the sampling strategy consisted of a series of orthogonal transects following a general South-toNorth salinity gradient, totaling 18 sampling locations from transects T\#1 to T\#7 (SI Fig.S2) (see also SI Table S2). A fine sediment deposition area (T\#8), the West Gironde mud patch, located approximately $50 \mathrm{~km}$ West to the mouth of the estuary, ${ }^{52}$ was also included in our survey to perform preliminary assessment of the PFAS transfer from the Gironde estuary to the Bay of Biscay continental shelf. At each sampling location, subsurface (1 $\mathrm{m}$ below surface) and bottom water (1 $\mathrm{m}$ above surficial sediments) samples were collected with a Niskin bottle. Sample temperature, $\mathrm{pH}$ and salinity were measured immediately, prior to onboard filtration through GF/F $(0.7 \mu \mathrm{m})$ filters using Nalgene ${ }^{\circledR}$ polyethylene filtration units. The filtrate was divided into two aliquots stored in high density polyethylene (HDPE) bottles, kept at $-20^{\circ} \mathrm{C}$ until analysis; filters were stored at $-20^{\circ} \mathrm{C}$ in aluminum trays until freeze-drying and analysis. In the case of dissolved organic carbon (DOC) and particulate organic carbon 
(POC), the filtration of water was performed on glass filtration units, and samples were then processed as described elsewhere. ${ }^{53,54}$ Composite subtidal sediment samples $(n=21)$ were collected with a Shipeck sediment grab sampler. In parallel, 13 additional composite bed sediment samples were collected at low tide across tidal mudflats, on both banks of the estuary (SI Fig.S2) (see also SI Table S2). Sediment characteristics were determined by the Laboratoire d'Analyses des Sols d'Arras (INRA). Grain size, organic carbon and organic nitrogen content were determined according to methods NF X 31-107, NF ISO 10694 and NF ISO 13878, respectively. Black carbon and iron oxides were both determined using in-house methods (see https://www6.lille.inra.fr/las/Methodes-d-analyse/Sols for further details).

\section{PFAS analysis}

Analytes were quantified using the isotopic dilution method, ISs being gravimetrically added to the samples and procedural blanks at the beginning of the extraction procedure. Full details on extraction and purification procedures are described elsewhere. ${ }^{30}$ Briefly, water samples $(0.5-1 \mathrm{~L})$ were concentrated using solid phase extraction on Strata X-AW cartridges; freeze-dried sediment $(1-2 \mathrm{~g})$ and SPM $(0.055-2.5 \mathrm{~g})$ samples underwent a microwave extraction with $10 \mathrm{~mL}$ of $\mathrm{MeOH}\left(10 \mathrm{~min}, 70^{\circ} \mathrm{C}\right)$ prior to ENVI-Carb graphite cleanup. Extracts were concentrated to $300 \mu \mathrm{L}\left(\mathrm{N}_{2}, 42^{\circ} \mathrm{C}\right)$, transferred to polypropylene injection vials, and stored at $-20^{\circ} \mathrm{C}$ until analysis.

Procedural blanks consisted of $500 \mathrm{~mL}$ of Vittel spring water and of $10 \mathrm{~mL}$ of $\mathrm{MeOH}$ for solid samples. When analytes were found in procedural blanks (SI Table S3), data were blankcorrected and the limit of detection (LOD) was determined as the standard deviation (SD) of the blanks multiplied by the $t_{n-1,95}$ Student coefficient. ${ }^{30}$ Otherwise, LODs were determined from the signal-to-noise ratio in low contaminated samples or in spiked matrices. LODs were in the range $0.0002-0.5 \mathrm{ng} \mathrm{L}^{-1}, 0.002-0.2 \mathrm{ng} \mathrm{g}^{-1} \mathrm{dw}$ and $0.001-0.03 \mathrm{ng} \mathrm{g}^{-1} \mathrm{dw}$ for water, SPM and sediment samples, respectively (SI Table S4). Recovery was controlled through the analysis of fortified Vittel spring water $(n=4)$ and Fontainebleau sand samples (surrogate for solid samples) ( $\mathrm{n}=4$ ), spiked at $1 \mathrm{ng} \mathrm{L}^{-1}$ or $1 \mathrm{ng} \mathrm{g}^{-1}$ dry weight $(\mathrm{dw})$ with target analytes, respectively, and were generally in the range 50-90\% (SI Table S5). Accuracy was also evaluated, and averaged $104 \pm 15 \%$ in water and $96 \pm 4 \%$ in solid samples for the compounds considered (SI Table S6).

PFAS chemical analyses were performed with an Agilent 1290 LC system interfaced with an Agilent 6490 triple quadrupole mass spectrometer (Agilent Technologies, Massy, France). 
Chromatographic conditions are described elsewhere, ${ }^{30}$ and mass spectrometry acquisition parameters are provided in the SI (Tables S7-S8).

\section{Statistics}

Statistical significance was set as $p<0.05$. Statistical tests and hierarchical clustering were performed with the $R$ statistical software (R version 2.15.3, R Core Team, 2013). In view of the presence of non-detects (data < LOD), functions from the "NADA" R-package were used to perform correlation and regression analyses. ${ }^{30}$ Note that compounds displaying more than $80 \%$ censored observations were not included in these analyses, since tenuous statistics may be obtained above this threshold. ${ }^{55}$

\section{Results and Discussion}

\section{Water Quality Parameters and Hydrology}

The evolution of water physicochemical parameters is shown in the SI (Fig.S3). Salinity increased from 2.1-2.3\% at Bec d'Ambès (T\#1) to 24.1-27.9 \%o near the mouth (T\#7). Suspended solids exhibited wide variations $\left(14-2,600 \mathrm{mg} \mathrm{L}^{-1}\right)$, the highest loads being found in the T\#3-T\#5 area where the SPM concentration averaged $320 \mathrm{mg} \mathrm{L}^{-1}$ in subsurface water and $1,450 \mathrm{mg} \mathrm{L}^{-1}$ near the bottom. Samples from transect $\mathrm{T} \# 8$ exhibited the general characteristics of marine environments (salinity: $32.9 \pm 0.4 \%$; SPM load $<40 \mathrm{mg} \mathrm{L}^{-1}$ ). POC and suspended solid loads were strongly linearly correlated $\left(R^{2}>0.998\right)$, indicating that the organic carbon fraction $\left(f_{o c}\right)$ was relatively constant over the salinity gradient (SI Fig.S4). DOC remained steadily at around $1.50 \pm 0.11 \mathrm{mg} \mathrm{L}^{-1}$ in the oligohaline to mesohaline area (T\#1-T\#5), decreased slightly to $1.20 \pm 0.14 \mathrm{mg} \mathrm{L}^{-1}$ in the polyhaline zone (T\#6-T\#7), and was below $1 \mathrm{mg} \mathrm{L}^{-1}$ offshore (T\#8). Over the sampling time, water flow rate, estimated as the combined discharges of the Garonne river at Tonneins and the Dordogne river at Pessacsur-Dordogne (data retrieved from <hydro.eaufrance.fr>), remained in the narrow range 280$289 \mathrm{~m}^{3} \mathrm{~s}^{-1}$, conditions typical of summer low-flow periods.

\section{Spatial Variations of PFAS Levels and Profiles}

Full details on detection frequencies and concentration ranges of individual PFASs in sediment, dissolved phase and SPM samples are provided in Table S9 of the SI. 
The highest PFAS level in sediment was that of PFOS (detection frequency $=100 \%$; mean = $0.43 \mathrm{ng} \mathrm{g}^{-1} \mathrm{dw}$; median $=0.47 \mathrm{ng} \mathrm{g}^{-1} \mathrm{dw}$ ), accounting for $30 \pm 5 \%$ on average of $\Sigma$ PFASs. Of these, an estimated $93 \%$ were attributed to the sole linear isomer, in excellent agreement with observations at French nationwide scale (88\%). ${ }^{30}$ PFOA, PFNA and PFDA were also frequently detected (88-100\%), and represented $11,7.5$, and $12 \%$ of $\Sigma$ PFASs on average, respectively. In contrast, PFASs of emerging concern such as FTSAs or diPAPs were only sporadically reported in these sediments (detection frequencies $<21 \%$ ). The spatial distribution of $\Sigma$ PFASs in sediment samples is illustrated in Fig.1a, while the spatial distribution of $\Sigma$ PFASs in sediment samples corrected for sediment organic carbon is shown in the SI (Fig.S5). $\Sigma$ PFASs in subtidal sediments was highly variable (range: $0.11-2.2 \mathrm{ng} \mathrm{g}^{-1}$ $\mathrm{dw}$; mean $=1.0 \pm 0.7 \mathrm{ng} \mathrm{g}^{-1} \mathrm{dw}$ ), while sediments from intertidal mudflats exhibited relatively high PFAS levels on both left and right banks (LPFASs range: $1.2-3.3 \mathrm{ng} \mathrm{g}^{-1} \mathrm{dw}$; mean $\Sigma$ PFASs $=2.3 \pm 0.7 \mathrm{ng} \mathrm{g}^{-1} \mathrm{dw}$ ). This was further confirmed by performing an independent $\mathrm{t}-$ test, the $p$-value of $0.002(<0.05)$ indicating a significant difference between the means of the two groups.

Hierarchical clustering on PFAS profiles in sediments (Ward's method, break in set at 4 clusters), resulted in clusters of size 12, 5, 9 and 8 (Fig.1b). Cluster \#01 grouped sites with high relative abundances of $\mathrm{C}_{4}-\mathrm{C}_{6}, \mathrm{C}_{7}-\mathrm{C}_{8}$ and $\mathrm{C}_{9}-\mathrm{C}_{11}$ PFCAs (each group representing $20 \%$ of $\Sigma$ PFASs) and essentially comprised intertidal sediments and upstream subtidal sediments. Cluster \#02 grouped subtidal sediments from the seaward end (T\#7) and offshore mudpatchs (T\#8) that maintained a high relative abundance of PFCAs (> $60 \%$ of $\Sigma$ PFASs) but differed from cluster \#01 by the higher proportion of some long-chain PFCAs $\left(\mathrm{C}_{9}-\mathrm{C}_{13}\right)$ compared to shorter-chain homologues. This suggests a sharp decrease of short-chain PFCA relative abundances in sediments when approaching the marine area, while those of $\mathrm{C}_{9}-\mathrm{C}_{13}$ PFCAs remain comparatively high as a result of salting out, a phenomenon which tends to be more pronounced with increasing perfluoroalkyl chain length under controlled conditions. ${ }^{56} \mathrm{~A}$ comparable upstream/downstream fractionation was observed for intertidal sediments, the $\mathrm{C}_{4}-\mathrm{C}_{6}$ to $\mathrm{C}_{9}-\mathrm{C}_{13}$ ratio dropping > 5-fold between Bayon-sur-Gironde (farther upstream right-bank site) and Talmont-sur-Gironde (farther downstream right-bank site), which seems to corroborate this hypothesis (SI Fig.S6). A similar short-chain versus longchain comparison could not be performed for the perfluoroalkl sulfonates, since only longchain PFSA congeners (i.e. $\geq \mathrm{C}_{6}$ ) were detected in the sediment. Additionally, the PFOS relative abundance exhibited little variations across the sediment sampling sites examined (Fig.1b). As regards the contribution of certain PFAA precursors, such as FOSA (for PFOS), or diPAPs and FTSAs (for PFCAs), it should be noted that the Pre-PFAAs targeted in the present survey displayed overall low contributions to the $\sum$ PFASs (e.g. median contribution 
of $\sum$ Pre-PFAAs in the sediment $=3.1 \%$ LPFASs). Despite this fact, it cannot be ruled out that the transformation of precursors -occurring either via microbially-mediated reactions or abiotic processes, including hydrolysis or photolysis- ${ }^{57-59}$ could partly explain the modifications to the PFCA molecular profiles along the estuary. Clusters \#03 and \#04 were characterized by higher abundances of PFOS and/or PFAA precursors, and mostly represented subtidal sediments from transects T\#3 through T\#6, all located in the MTZ.

The concentrations of PFASs in the dissolved phase and SPM of subsurface and bottom water samples along the salinity gradient are shown in Fig.2, showing a sharp decrease of ¿PFAS in the dissolved phase in the lower estuary (T\#5-T\#7), while the intra-estuarine (T\#1-T\#7) fluctuations of $\Sigma$ PFAS in the SPM did not show such a gradient. In the water column (dissolved phase + SPM), $\Sigma_{\text {wcol }}$ PFASs ranged between $0.26-9.3 \mathrm{ng} \mathrm{L}^{-1}$ and $0.11-14$

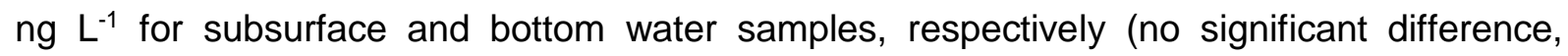
Wilcoxon signed-rank test). A general downstream/upstream gradient was observed for intraestuary sites, $\Sigma_{\text {wcol }}$ PFASs decreasing linearly with increasing salinity as a result of dilution (SI Fig.S7). Negative linear trends $\left(R^{2}=0.64-0.92\right)$ were also observed between individual compounds in the water column and salinity (data not shown). On average, PFOS was the predominant compound in the water column $(33 \pm 5 \%$ and $34 \pm 8 \%$ of $\Sigma$ PFASs for subsurface and bottom water samples, respectively).

In the dissolved phase, $\Sigma$ PFASs ranged between $0.077-8.3 \mathrm{ng} \mathrm{L}^{-1}$, with individual analytes generally found in the sub $\mathrm{ng} \mathrm{L}^{-1}$ range (see also SI Table S9). Abundance profiles in the dissolved phase remained essentially the same along the salinity gradient (Fig.2). Br-PFOS was the prevalent compound on average in the dissolved phase, followed by PFHxS, PFHxA and L-PFOS (16 $\pm 6,14 \pm 3,11 \pm 6$ and $11 \pm 5 \%$ of $\Sigma$ PFASs, respectively). Among emerging PFASs, 6:2 FTSA was the most frequently detected compound but its median contribution to ¿PFASs was $0.6 \%$ only.

In the SPM, ¿PFASs ranged between 3.3-10 $\mathrm{ng} \mathrm{g}^{-1} \mathrm{dw}$ and 2.8-6.1 $\mathrm{ng} \mathrm{g}^{-1} \mathrm{dw}$ for subsurface and bottom water samples, respectively (Fig.2). PFAS levels in SPM of bottom water samples exceeded those in corresponding bed sediment samples by a median ratio (SPM / bed sediment) of 1.6-2.9 for PFCAs and 4.9-6.7 for PFHxS and PFOS. Likewise, median PFAS concentration ratios between the SPM of surface and bottom water samples were in the narrow range 1.1-1.6 and 1.6-2.1 for PFCAs and PFSAs, respectively. These contrasting PFAS levels in the SPM are likely a consequence of the segregation of fine and coarse particles along the vertical profile, leading to differences in SPM specific surface 
area. ${ }^{33}$ PFOS was systematically detected in suspended solid samples and accounted for $60 \pm 12 \%$ of $\Sigma$ PFASs on average (L-PFOS $=64 \pm 6 \%$ of total PFOS). Equally noteworthy was the occurrence of PFDA and PFOA in the SPM (detection frequency > 95\%), albeit at lower relative abundances ( $9 \%$ of $\Sigma$ PFASs each).

\section{Spatial and Physico-chemical Factors Underlying Sediment PFAS Levels}

PFAS analytes with censoring percentages $>80 \%$ were not considered in the present section. ${ }^{30}$ In addition to spatial considerations (e.g., distance from nearest major upstream sources located in the Bordeaux conurbation), PFAS sediment levels may be influenced by a variety of sediment-specific characteristics. A strong collinearity was observed between the fine fraction content (mass percent fraction of the $<20 \mu \mathrm{m}$ fraction over the $<2 \mathrm{~mm}$ fraction) (grain size) and other sediment ancillary data including organic carbon fraction ( $\left.f_{O C}\right)$, organic nitrogen content (NO) or iron oxides (FeOx) $\left(\mathrm{R}^{2}=0.92-0.98\right)$ (SI Table S10). In contrast, relationships between black carbon content (carbon soot) and sediment grain size or $f_{O C}$ were much weaker $\left(R^{2}<0.50\right)$. Therefore, the only sediment quality parameters retained in the preliminary correlation analysis were $f_{O C}$ and carbon soot. Significant correlations between PFAS levels in sediments and $f_{O C}$ were observed for $13 / 14$ of the considered compounds with relatively high correlation coefficients (Kendall's $\mathrm{T}>0.50$ ), except for $\mathrm{C}_{5}-\mathrm{C}_{7}$ PFCAs (Kendall's $\mathrm{T}=0.29-0.44)$ (SI Table S11). The highest significance was observed for PFUnDA and L-PFOS (Kendall's $\mathrm{T}=0.65-0.71$ ), the slope of the cenken regression amounting to 1.2 and 4.2 , respectively, of the same magnitude than previous observations at French nationwide scale. ${ }^{30}$ Significant correlations were also observed for $14 / 14$ of the considered compounds when examining PFAS levels in sediments and carbon soot, albeit with lower Kendall's $\mathrm{T}$ correlation coefficients (0.35-0.45 for most compounds) (SI Table S12). Overall, these results provide further evidence that under estuarine conditions PFASs are mainly associated with fine-grained sediment exhibiting higher organic carbon content (as well as iron oxides in our case); black carbon content also appeared as a significant factor, yet less predominant than $f_{O C}$.

The combined influence of $f_{O C}\left(\mathrm{X}_{1}\right)$ and distance from upstream sources $\left(\mathrm{X}_{2}\right)$ (arbitrarily set at zero for sampling site T\#1) on PFAS levels in the sediment ( $Y$ ) was assessed via multiple regression with a specific statistical treatment for non-detects. ${ }^{55}$ The following model was used: $\ln (1+Y)=\alpha+\beta^{*} X_{1}+Y^{*} X_{2}$, via the cenreg function from the NADA R-package. With the exception of EtFOSAA, the model was significant for all the compounds considered, with high likelihood correlation coefficients (Loglik-R $=0.60-0.92$ ) (SI Table S13). Significant coefficients were near-systematically observed for $X_{1}$ and $X_{2}, \beta$ and $\gamma$ having opposite signs 
as anticipated. The relative importance of $\beta$ and $y$ varied according to perfluoroalkyl chain length, $f_{O C}$ being a more important controlling factor than distance from upstream sources for $\mathrm{C}_{8}-\mathrm{C}_{13}$ PFCAs and L-PFOS, while these two factors were of nearly equal weight for $\mathrm{C}_{5}-\mathrm{C}_{7}$ PFCAs, PFHxS and Br-PFOS (SI Table S13). This may be attributed to the intense hydrosedimentary dynamics in this system. ${ }^{33,47}$

\section{Partitioning Behavior in the Water Column}

Investigating the water-solid phase distribution of PFASs is of fundamental importance to further predict their environmental fate; such modeling is not an easy task since PFAS sorption may be driven by sorbent-, sorbate- and solution-specific parameters. ${ }^{27,60}$ However, methodological issues may arise that could bias a rigorous determination of partitioning coefficients. In laboratory-based sorption/desorption experiments, for instance, the study of very high aqueous PFAS concentrations - albeit providing the possibility of readily analyzing the dissolved phase concentration with no need for pre-concentration - may not be always representative of environmental conditions. ${ }^{60}$ Additionally, the possibility of sorption of certain analytes onto the container material itself has been previously reported and should not be overlooked in the mass balance. ${ }^{27}$ Separating the dissolved and solid phases, for instance through filtration, could entail other pitfalls. Contamination issues at the filtration stage may produce artificially higher dissolved phase PFAS concentrations, which may be rectified by pre-cleaning the membrane filters. ${ }^{61}$ In the present study, filtration blanks were performed on board in parallel to real sample filtration, showing no particular contamination for either media (i.e. dissolved phase and filters) with respect to corresponding laboratory procedural blanks. A further caveat relates to the possible retention of dissolved phase PFASs into the filtration membrane, which may lead to overestimating the $K_{D}$. The impact of filter nature on this filtration artifact has been previously examined for a suite of anionic PFASs, showing that glass, rather than nylon, would better preserve the integrity of dissolved phase concentrations. ${ }^{61,62}$ Chandramouli et al. ${ }^{62}$ cautioned, however, that significant filtration artifacts could still be obtained with glass filters for particular analytes, including diPAPs. Another important aspect to consider in our particular case is the differential salinity content between water samples, and the possible influence of the latter on the so-called filtration artifact. A matrix-specific test was performed using pre-filtered river water samples spiked with PFASs (50 ng L-1 each), adjusted at 10 and $35 \%$ salinity with sea salt, and passed through glass fiber filters. Regardless of salinity, sorption was negligible $(<10 \%)$ for most analytes, moderate (10-35\%) for a series of long-chain PFASs (e.g. $\mathrm{C}_{11}-\mathrm{C}_{14}$ PFAAs, N-alkyl 
FOSAAs, FOSA, MeFOSA and EtFOSA) and severe for diPAPs (> 65\%). In view of the aforementioned findings, diPAPs were not considered in the partitioning study.

Suspended sediment-water partitioning coefficients $\left(K_{D}\right)$ were calculated as the ratio of the concentration in the SPM ( $\mathrm{ng} \mathrm{kg}^{-1}$ ) to that in the dissolved phase $\left(\mathrm{ng} \mathrm{L}^{-1}\right)$, provided that the compound could be determined in both compartments for a particular sample ("matching pairs" method). The suspended sediment-water partitioning coefficient normalized to carbon content $\left(K_{O C}\right)$ was derived from the following equation: $K_{O C}=K_{D} \times 100 / f_{O C}$, where $f_{O C}$ is the sediment organic carbon fraction. Average Log $K_{D}$ and $\log K_{O C}$ were in the range 1.3-3.8 and 3.2-5.6 for the compounds considered, respectively (Table 1). The Log $K_{D}$ of $\mathrm{C}_{4}-\mathrm{C}_{8}$ PFSAs was linearly correlated to perfluoroalkyl chain length $\left(R^{2}=0.94\right.$; slope $\left.=0.57 \pm 0.10\right)$. As regards PFCAs, Log $K_{D}$ and perfluoroalkyl chain length were also positively correlated from PFHpA to PFUnDA $\left(R^{2}=0.93\right.$; slope $\left.=0.31 \pm 0.05\right)$, the regression line yielding a slope in the same order of magnitude than values from Labadie and Chevreuil ${ }^{21}$ or Kwadijk et al. ${ }^{29}$ Shorter-chain PFCAs $\left(\mathrm{C}_{4}-\mathrm{C}_{6}\right)$ differed from this trend, average Log $K_{D}$ remaining in the same range as that of PFHpA. This is consistent with previous observations that short-chain PFCAs do not follow the typical chain-length dependency as regards sorption to soils or sediments. ${ }^{21,63}$ This may also indicate that, for short chain carboxylates, the sorption process is dominated by electrostatic interactions between the carboxylic group and charged moieties on sediment particles, rather than hydrophobic interactions.

The PFAS particle-related fraction $(\varphi)$ was determined as the ratio of the concentration in the SPM (ng L-1) to the total PFAS concentration in the water (dissolved + SPM, $n \operatorname{L~L}^{-1}$ ). On average, $\varphi$ was in the range $18-80 \%$ and $1.3-43 \%$ for $C_{4}-C_{11}$ PFCAs and $C_{4}-C_{8}$ PFSAs, respectively (Table 1). The spatial evolution of $\varphi$ along transects T\#1 through T\#8 is illustrated in Fig.3. $\varphi$ increased concomitantly with the suspended solid load, following a peak-shape curve with maximum values within the estuarine MTZ.

\section{Particle-concentration effect and salting-out influence on PFAS partitioning}

The influence of environmental parameters on the suspended solid-water partitioning coefficient $\left(K_{D}\right)$ was investigated. Note that water samples from the intra-estuary zone only (i.e. transects $\mathrm{T} \# 1$ through $\mathrm{T} \# 7$ ) were considered to this end. $K_{D}$ was negatively correlated with SPM; the decrease in $K_{D}$ was especially sharp when suspended solids varied in the range $<0.02-0.5 \mathrm{~g} \mathrm{~L}^{-1}$, and remained constant for higher SPM loads $\left(>1 \mathrm{~g} \mathrm{~L}^{-1}\right.$ ), akin to observations under controlled conditions by Ahrens et al. ${ }^{64}$ who reported little variation in Log $K_{D}$ coefficients for SPM loads between 1 and $100 \mathrm{~g} \mathrm{~L}^{-1}$. Bowman et al. ${ }^{65}$ previously reported a 
so-called "third-phase effect" for estrogens under estuarine conditions, the enhanced apparent dissolved concentrations at high SPM concentrations being due to the increased presence of colloids. Although the dataset gathered in the present study would not allow to evaluate this hypothesis, the PFAS-colloid interaction is presumably much weaker than for other contaminants such as polycyclic aromatic hydrocarbons or polychlorobiphenyls that are less water soluble. In addition, the PFAS-DOC association is unlikely the driving factor for the relationship observed between $K_{D}$ and SPM, at least for two reasons: i) the samples collected within the estuary displayed a rather limited range of DOC values $(1.3 \pm 0.2 \mathrm{mg} / \mathrm{L})$; and ii) the DOC levels required to deviate substantially true $K_{D}$ from apparent $K_{D}$ were previously shown for selected PFASs to be at least two orders of magnitude higher than the DOC values reported in the present study. ${ }^{27}$ There is, however, another possibility to explain the decrease in $K_{D}$ with increasing SPM load. When suspended sediment concentrations increase, flocculation (aggregation of SPM particles) may be enhanced to such an extent that a sharp decrease of SPM specific surface area -and available OM, for that matter- can ensue, independently of salinity. ${ }^{66,67}$ This phenomenon is known to occur in the Gironde estuary (Gibbs et al. 1989) as well as in other estuarine and riverine hydrosystems, ${ }^{68,69}$ and may be the underlying mechanism to explain our observations. A power function fitting was used to describe the decrease of $K_{D}$ with increasing suspended solid concentration in water $\left(K_{D}=a_{S P M}{ }^{-b}\right)$ (where $a$ and $b$ are numerical constants $\left.>0\right)$, following empirical models previously established for other organic contaminants. ${ }^{38}$ An illustration is provided in Fig.4 and full details are given in the SI (Table S14).

In addition to the particle-concentration effect, salinity has also been reported as an influential controlling factor of organic compound sorption to sediments, including PFASs. ${ }^{24-}$ 26, 70 The increase in salinity has been reported to produce "salting-out" effects (decrease in aqueous solubility with increasing ionic strength. ${ }^{38,39}$ Increasing salinity is also expected to reduce the electrostatic repulsion between anionic PFAS and negatively charged surfaces (iron oxides, natural organic matter) via bridging with divalent cations present in sea water $\left(\mathrm{Mg}^{2+}, \mathrm{Ca}^{2+}\right){ }^{71} K_{D}$ was related to salinity (S, mass basis) through a "salting out" constant ( $\left.\sigma_{\text {ads }}{ }^{*}, L g^{-1}\right)$ using the following model: $K_{D}=K^{\circ}{ }_{D} \mathrm{x} \exp \left(2.303 \sigma_{\text {ads }}{ }^{*} \mathrm{~S}\right)$, with $K_{D}$ the relative solubility in saline water and $K^{\circ}$ that extrapolated in freshwater (Fig.4). The conversion to a salting constant on a molar basis $\left(\delta, \mathrm{L} \mathrm{mol}^{-1}\right)$ can be completed as per Turner and Rawling. ${ }^{38}$ $\delta$ was in the range 1.79-2.61 for the compounds considered (Table 1), in line with fieldderived values by Hong et al. ${ }^{25}$ in the Youngsan and Nakdong river estuaries (South Korea) $\left(\mathrm{SPM}=8.1-130 \mathrm{mg} \mathrm{L}^{-1}\right.$; salinity $=0.12-29 \%$; $\left.\delta=1.34-2.57 \mathrm{~L} \mathrm{~mol}^{-1}\right)$. Overall, the $K^{\circ}{ }_{D}$ values reported in the present study are also in good agreement with average freshwater-sediment $K_{D}$ coefficients determined for 133 rivers and lakes at nationwide scale in France. ${ }^{30}$ 
In an attempt to combine both the particle-concentration effect and the salinity dependence, the following model was used: $K_{D}=a_{S P M}{ }^{-b} \times \exp \left(2.303 \sigma_{a d s}{ }^{*} \times S\right)$, wherein the particleconcentration effect (magnitude of $b$ ) is assumed to be independent of salinity. ${ }^{38}$ This expression can be readily transformed to $L n K_{D}=k_{0}+k_{1} X_{1}+k_{2} X_{2}$, where $X_{1}=L n(S P M)$ and $\mathrm{X}_{2}=\mathrm{S}$. A multiple linear regression model was fitted to the dataset to derive therefrom $\mathrm{a}=$ $\exp \left(k_{0}\right), b=-k_{1}$, and $\sigma_{a d s}{ }^{*}=k_{2} / 2.303$, and the model proved significant for 8 compounds (see SI Table S15 for details). The model was then validated using a previously acquired dataset (2012-2013) during a temporal follow-up of PFASs at Pauillac, a sampling station located in the oligohaline zone of the Gironde estuary. ${ }^{23}$ Predicted Log $K_{D}$ values yielded by the model from the HALOGIR 2014 survey were in overall good agreement with field data from the 2012-2013 survey (SPM range: 132-1916 $\mathrm{mg} \mathrm{L}^{-1}$; salinity range: 0-11.6 \%o) (SI Fig.S8).

\section{Significance}

The spatial distribution and partitioning behavior of PFASs were investigated along a salinity/turbidity gradient in a macrotidal estuary. PFASs were found ubiquitously in this hydrosystem, albeit at relatively low levels since $\sum$ PFASs remained in the range $0.1-14 \mathrm{ng} \mathrm{L}$ ${ }^{1}$ in the water column and 0.1-3.3 $\mathrm{ng} \mathrm{g}^{-1} \mathrm{dw}$ in the sediment. Short-chain PFCAs and PFSAs were dominant in the dissolved phase, while L-PFOS generally prevailed in sediments, in overall excellent agreement with PFAS patterns usually observed in hydrosystems. ${ }^{30}$ Besides the intrinsic hydrophilic properties of $\mathrm{C}_{4}-\mathrm{C}_{6}$ PFCAs, the relatively high abundance of these compounds in the dissolved phase could be attributed to recent shifts in PFAS production toward shorter-chain congeners due to the gradual phase-out of $\mathrm{C}_{8}$-based PFAS chemistries. ${ }^{72}$ In addition, $\mathrm{C}_{4}-\mathrm{C}_{6}$ PFCAs could also result from the degradation of precursors not monitored in the present survey. ${ }^{8-10,58,59}$

Sediment organic carbon fraction (highly correlated to grain-size and other sediment quality parameters) appeared as the primary controlling factor of PFAS levels in the sediment, while the distance from upstream sources seemed less critical. On average, $\Sigma$ PFASs in the SPM was $\sim 10$ times greater than that of bed sediments. Thus, given the relatively high suspended solid loads in the MTZ (up to $2600 \mathrm{mg} \mathrm{L}^{-1}$ ) and spatial extent of the latter (>10 km), ingestion of suspended sediment could be a key PFAS exposure pathway for both benthic (sedimentdwelling) and pelagic biota in highly turbid estuaries.

Water-suspended sediment partitioning of PFASs appeared tightly influenced by suspended solid loads and salinity. Hence, seasonal variations in the MTZ position are expected to exert a strong influence on PFAS retention, sequestration being likely enhanced when the MTZ is 
located near the seaward end of the estuary due to salting-out. ${ }^{67}$ Building upon mechanistic knowledge regarding the fate of other organic contaminants in estuaries, ${ }^{38}$ models of $K_{D}$ were derived, integrating both particle-concentration and salinity effects. These empirical models were further validated using an independent dataset collected under contrasted geochemical conditions within the same estuary. Since input data are usually readily available or simulated for salinity or SPM, this model would thus appear useful to implement numerical modeling of PFAS environmental fate in transitional waters, ${ }^{73-76}$ involving models that incorporate both PFAS partitioning and 3D-hydrosedimentary dynamics. ${ }^{77}$ 


\section{Acknowledgments}

The authors gratefully acknowledge the crew from the research vessel Côtes de la Manche (CNRS/INSU), as well as the following colleagues for their contribution to field work and analytical support: Gwenael Abril, Hervé Derriennic, Mathilde Lauzent, Riccardo Massei, Clara Michaud, Patrick Pardon, Edith Parlanti and Dominique Poirier. This study has been carried out with financial support from the French national Agency (ANR), in the frame of the 'Investments for the Future' programme, within the Cluster of Excellence COTE (ANR-10-LABX-45). IdEx Bordeaux (ANR-10-IDEX-03-02) provided the PhD grant allocated to G. Munoz. The authors also acknowledge funding from CNRS (EC2CO-Ecodyn INSU) and ORQUE SUDOE (SOE3/P2/F591), as well as the Aquitaine Regional Council and the European Union (CPER A2E project). Europe is moving in Aquitaine with the European Regional Development Fund (FEDER).

\section{Associated content}

Supporting Information. Chemicals and materials, Details on targeted analytes and internal standards, MS/MS operating parameters, QA/QC, Analytical method validation, Maps presenting the sampling strategy, Water ancillary parameters, Relation between SPM load and POC, Spatial distribution of ¿PFAS corrected to sediment OC, Summary of PFAS occurrence and levels in water and sediment, Correlation matrix between sediment quality parameters, Multiple regression results of controlling factors of PFAS sediment levels, Regression results of $K_{D}$ and particle concentration effect, Modeling of $K_{D}$ combining both particle concentration effect and salting out. 


\section{References}

[1] Barzen-Hanson, K. A.; Field, J. A. Discovery and implications of C2 and C3 perfluoroalkyl sulfonates in aqueous film-forming foams and groundwater. Environ. Sci. Technol. Lett. 2015, 2, 9599.

[2] Barzen-Hanson, K. A.; Roberts, S. C.; Choyke, S.; Oetjen, K.; McAlees, A.; Riddell, N.; McCrindle, R.; Lee Ferguson, P.; Higgins, C. P.; Field, J. A. Discovery of 40 Classes of Per- and Polyfluoroalkyl Substances in Historical Aqueous Film-Forming Foams (AFFFs) and AFFF-Impacted Groundwater. Environ. Sci. Technol. 2017, 51, 2047-2057.

[3] Buck, R. C.; Franklin, J.; Berger, U.; Conder, J. M.; Cousins, I. T.; De Voogt, P. Perfluoroalkyl and polyfluoroalkyl substances in the environment: terminology, classification and origins. Integr. Environ. Assess. Manag. 2011, 7, 513-541.

[4] D'Agostino, L. A.; Mabury, S. A. Identification of novel fluorinated surfactants in aqueous film forming foams and commercial surfactant concentrates. Environ. Sci. Technol. 2014, 48, 121-129.

[5] Lindstrom, A. B.; Strynar, M. J.; Libelo, E. L. Polyfluorinated compounds: past, present, and future. Environ. Sci. Technol. 2011, 45, 7954-7961.

[6] Field, J. A.; Johnson, C. A.; Rose, J. B. What is "emerging"? Environ. Sci. Technol. 2006, 40, 7105-7105.

[7] Wang, Z.; DeWitt, J. C.; Higgins, C. P.; Cousins, I. T. A Never-Ending Story of Per-and Polyfluoroalkyl Substances (PFASs)? Environ. Sci. Technol. 2017, 51, 2508-2518.

[8] Liu, J.; Mejia-Avendaño, S. Microbial degradation of polyfluoroalkyl chemicals in the environment: A review. Environ. Int. 2013, 61, 98-114.

[9] Harding-Marjanovic, K. C.; Houtz, E. F.; Yi, S.; Field, J. A.; Sedlak, D. L.; Alvarez-Cohen, L. Aerobic biotransformation of fluorotelomer thioether amido sulfonate (Lodyne) in AFFF-amended microcosms. Environ. Sci. Technol. 2015, 49, 7666-7674.

[10] Mejia-Avendaño, S.; Vo Duy, S.; Sauvé, S.; Liu, J. Generation of perfluoroaklyl acids from aerobic biotransformation of quaternary ammonium polyfluoroalkyl surfactants. Environ. Sci. Technol. 2016, 50, 9923-9932.

[11] Houde, M.; De Silva, A. O.; Muir, D. C. G.; Letcher, R. J. Monitoring of Perfluorinated Compounds in Aquatic Biota: An Updated Review. Environ. Sci. Technol. 2011, 45, 7962-7973.

[12] Rich, C. D.; Blaine, A. C.; Hundal, L.; Higgins, C. P. Bioaccumulation of perfluoroalkyl acids by earthworms (Eisenia fetida) exposed to contaminated soils. Environ. Sci. Technol. 2015, 49, 881-888.

[13] Munoz, G.; Labadie, P.; Botta, F.; Lestremau, F.; Lopez, B.; Geneste, E.; Pardon, P.; Dévier, M. $\mathrm{H}$.; Budzinski, H. Occurrence survey and spatial distribution of perfluoroalkyl and polyfluoroalkyl surfactants in groundwater, surface water, and sediments from tropical environments. Sci. Total Environ. 2017, 607, 243-252.

[14] Lescord, G. L.; Kidd, K. A.; De Silva, A. O.; Williamson, M.; Spencer, C.; Wang, X.; Muir, D. C. G. Perfluorinated and polyfluorinated compounds in lake food webs from the Canadian high arctic. Environ. Sci. Technol. 2015, 49, 2694-12702. 
[15] Llorca, M.; Farré, M.; Tavano, M. S.; Alonso, B.; Koremblit, G.; Barceló, D. Fate of a broad spectrum of perfluorinated compounds in soils and biota from Tierra del Fuego and Antarctica. Environ. Pollut. 2012, 163, 158-166.

[16] Yeung, L. W. Y.; Dassuncao, C.; Mabury, S. A.; Sunderland, E. M.; Zhang, X.; Lohmann, R. Vertical Profiles, Sources and Transport of PFASs in the Arctic Ocean. Environ. Sci. Technol. 2017, $51,6735-6744$.

[17] Ellis, D. A.; Martin, J. W.; De Silva, A. O.; Mabury, S. A.; Hurley, M. D.; Sulbaek Andersen, M. P.; Wallington, T. J. Degradation of fluorotelomer alcohols: a likely atmospheric source of perfluorinated carboxylic acids. Environ. Sci. Technol. 2004, 38, 3316-3321.

[18] Yamashita, N.; Taniyasu, S.; Petrick, G.; Wei, S.; Gamo, T.; Lam, P.K.S. Perfluorinated acids as novel chemical tracers of global circulation of ocean waters. Chemosphere 2008, 70, 1247-1255.

[19] Field, J. A.; Seow, J. Properties, Occurrence, and Fate of Fluorotelomer Sulfonates. Critical Reviews in Environmental Science and Technology 2017, http://dx.doi.org/10.1080/10643389.2017.1326276

[20] Ahrens, L.; Taniyasu, S.; Yeung, L. W. Y.; Yamashita, N.; Lam, P. K. S.; Ebinghaus, R. Distribution of polyfluoroalkyl compounds in water, suspended particulate matter and sediment from Tokyo Bay, Japan. Chemosphere 2010, 79, 266-272.

[21] Labadie, P.; Chevreuil, M. Partitioning behavior of perfluorinated alkyl contaminants between water, sediment and fish in the Orge River (nearby Paris, France). Environ. Pollut. 2011, 159, 391397.

[22] Zhang, Y.; Meng, W.; Guo, C.; Xu, J.; Yu, T.; Fan, W.; Li, L. Determination and partitioning behavior of perfluoroalkyl carboxylic acids and perfluorooctanesulfonate in water and sediment from Dianchi Lake, China. Chemosphere 2012, 88, 1292-1299.

[23] Munoz, G.; Babut, M.; Lobry, J.; Selleslagh, J.; Geneste, E.; Pardon, P.; Budzinski, H.; Labadie, $P$. One-year monitoring of temporal variations and partitioning behavior of poly- and perfluoroalkyl substances between water, suspended particulate matter and biota in a macrotidal estuary: case study on the Gironde. Personal communication.

[24] Jeon, J.; Kannan, K.; Lim, B.J.; An, K.G.; Kim, S.D. Effects of salinity and organic matter on the partitioning of perfluoroalkyl acid (PFAs) to clay particles. J. Environ. Monit. 2011, 13, 1803-1810.

[25] Hong, S.; Khim, J. S.; Park, J.; Kim, M.; Kim, W. K.; Jung, J.; Hyun, S.; Kim, J. G.; Lee, H.; Choi, H. J.; Codling, G.; Giesy, J. P. In situ fate and partitioning of waterborne perfluoroalkyl acids (PFAAs) in the Youngsan and Nakdong River Estuaries of South Korea. Sci. Total Environ. 2013, 445-446, $136-145$.

[26] Wang, S.; Wang, H.; Deng, W. Perfluorooctane sulfonate (PFOS) distribution and effect factors in the water and sediment of the Yellow River Estuary, China. Environ. Monit. Assess. 2013, 185, 85178524.

[27] Higgins, C. P.; Luthy, R. G. Sorption of Perfluorinated Surfactants on Sediments. Environ. Sci. Technol. 2006, 40, 7251-7256.

[28] Ahrens, L.; Yamashita, N.; Yeung, L. W. Y.; Taniyasu, S.; Horii, Y.; Lam, P. K. S.; Ebinghaus, R. Partitioning Behavior of per- and Polyfluoroalkyl Compounds between Pore Water and Sediment in Two Sediment Cores from Tokyo Bay, Japan. Environ. Sci. Technol. 2009, 43, 6969-6975. 
[29] Kwadijk, C. J. A. F.; Korytár, P.; Koelmans, A. A. Distribution of Perfluorinated Compounds in Aquatic Systems in the Netherlands. Environ. Sci. Technol. 2010, 44, 3746-3751.

[30] Munoz, G.; Giraudel, J. L.; Botta, F.; Lestremau, F.; Dévier, M. H.; Budzinski, H.; Labadie, P. Spatial distribution and partitioning behavior of selected poly- and perfluoroalkyl substances in freshwater ecosystems: A French nationwide survey. Sci. Total Environ. 2015, 517, 48-56.

[31] Chen, H.; Chen, S.; Quan, X.; Zhao, Y.; Zhao, H. Sorption of perfluorooctane sulfonate (PFOS) on oil and oil-derived black carbon: Influence of solution pH and [Ca 2+]. Chemosphere 2009, 77, 1406-1411.

[32] Zhi, Y.; Liu, J. Adsorption of perfluoroalkyl acids by carbonaceous adsorbents: Effect of carbon surface chemistry. Environ. Pollut. 2015, 202, 168-176.

[33] Turner, A.; Millward, G.E. Suspended particles: their role in estuarine biogeochemical cycles. Estuar. Coast Shelf Sci. 2002, 55, 857-883.

[34] Kan, A. T.; Fu, G.; Tomson, M .B. Adsorption/desorption hysteresis in organic pollutant and soil/sediment interaction. Environ. Sci. Technol. 1994, 28, 859-867.

[35] Chapman, P. M.; Wang, F.; Caeiro, S. S. Assessing and managing sediment contamination in transitional waters. Environ. Int. 2013, 55, 71-91.

[36] Cancino, L.; Neves, R. Hydrodynamic and sediment suspension modelling in estuarine systems. Part II: Application to the Western Scheldt and Gironde estuaries. J. Mar. Syst. 1999, 22, 117-131.

[37] Audry, S.; Blanc, G.; Schäfer, J.; Guérin, F.; Masson, M.; Robert, S. Budgets of Mn, Cd and Cu in the macrotidal Gironde estuary (SW France). Mar. Chem. 2007, 107, 433-448.

[38] Turner, A.; Rawling, M. C. The influence of salting out on the sorption of neutral organic compounds in estuaries. Wat. Res. 2001, 35, 4379-4389.

[39] Turner, A. Salting out of chemicals in estuaries: implications for contaminant partitioning and modelling. Sci. Total Environ. 2003, 314, 599-612.

[40] Lobry, J.; Mourand, L.; Rochard, E.; Elie, P. Structure of the Gironde estuarine fish assemblages: a comparison of European estuaries perspective. Aquatic Living Res. 2003, 16, 47-58.

[41] Selleslagh, J.; Lobry, J.; N'Zigou, A. R.; Bachelet, G.; Blanchet, H.; Chaalali, A.; Sautour, B.; Boët, P. Seasonal succession of estuarine fish, shrimps, macrozoobenthos and plankton: Physicochemical and trophic influence. The Gironde estuary as a case study. Est. Coast. Shelf Sci. 2012, 112, 243-254.

[42] Munoz, G.; Budzinski, H.; Babut, M.; Drouineau, H.; Lauzent, M.; Le Menach, K.; Lobry, J.; Selleslagh, J.; Simonnet-Laprade, C.; Labadie, P. Evidence for the Trophic Transfer of Perfluoroalkylated Substances in a Temperate Macrotidal Estuary. Environ. Sci. Technol. 2017, 51, 8450-8459.

[43] Allen, G. P.; Castaing, P. Suspended sediment transport from the Gironde estuary (France) into the adjacent continental shelf. Mar. Geol. 1973, 14, 47-53.

[44] Allen, G. P.; Salomon, J. C.; Bassoullet, P.; Du Penhoat, Y.; De Grandpré, C. Effects of tides on mixing and suspended sediment transport in macrotidal estuaries. Sedim. Geol. 1980, 26, 69-90.

[45] Kraepiel, A. M.; Chiffoleau, J. F.; Martin, J. M.; Morel, F. M. Geochemistry of trace metals in the Gironde estuary. Geochim. Cosmochim. Acta 1997, 61, 1421-1436. 
[46] Abril, G.; Etcheber, H.; Le Hir, P.; Bassoullet, P.; Boutier, B.; Frankignoulle, M. Oxic/anoxic oscillations and organic carbon mineralization in an estuarine maximum turbidity zone (The Gironde, France). Limnol. Oceanogr. 1999, 44, 1304-1315.

[47] Sottolichio, A.; Castaing, P. A synthesis on seasonal dynamics of highly-concentrated structures in the Gironde estuary. C.R. Acad. Sci. 1999, Sér. II Fasc.A-Sci. Terre Planètes 329, 795-800.

[48] Jouanneau, J. M.; Latouche, C. The Gironde Estuary, 1981, pp.1-115. In Fürchtbauer, H., Lisitzyn, A.P., Millerman, J.D., Seibold, E. [eds.], Contribution to sedimentology 10. E. Sweizerbart'sche Verlagsbuchhandlung, Stuttgart.

[49] Lanceleur, L.; Schäfer, J.; Chiffoleau, J. F.; Blanc, G.; Auger, D.; Renault, S.; Baudrimont, M.; Audry, S. Long-term records of cadmium and silver contamination in sediments and oysters from the Gironde fluvial-estuarine continuum-Evidence of changing silver sources. Chemosphere 2011, 85, 1299-1305.

[50] Tapie, N.; Le Menach, K.; Pasquaud, S.; Elie, P.; Devier, M. H.; Budzinski, H. PBDE and PCB contamination of eels from the Gironde estuary: From glass eels to silver eels. Chemosphere 2011, 83, 175-185.

[51] Bodin, N.; Tapie, N.; Le Ménach, K.; Chassot, E.; Elie, P.; Rochard, E.; Budzinski, H. PCB contamination in fish community from the Gironde Estuary (France): Blast from the past. Chemosphere 2014, 98, 66-72.

[52] Gadel, F.; Jouanneau, J. M.; Weber, O.; Serve, L.; Comellas, L. Traceurs organiques dans les dépôts de la vasière Ouest-Gironde (Golfe de Gascogne). Oceanol. Acta 1997, 20, 687-695.

[53] Abril, G.; Nogueira, M.; Etcheber, H.; Cabecadas, G.; Lemaire, E.; Brogueira, M. J. Behaviour of Organic Carbon in Nine Contrasting European Estuaries. Est. Coast. Shelf Sci. 2002, 54, 241-262.

[54] Huguet, A.; Vacher, L.; Relexans, S.; Saubusse, S.; Froidefond, J. M.; Parlanti, E. Properties of fluorescent dissolved organic matter in the Gironde Estuary. Org. Geochem. 2009, 40, 706-719.

[55] Helsel, D. 2012. Statistics for Censored Environmental Data Using Minitab and R, 2nd ed. Wiley.

[56] Jeon, J.; Kannan, K.; Lim, H. K.; Moon, H. B.; Ra, J. S.; Kim, S. D. Bioaccumulation of perfluorochemicals in pacific oyster under different salinity gradients. Environ. Sci. Technol. 2010, 44, 2695-2701.

[57] Moe, M. K.; Huber, S.; Svenson, J.; Hagenaars, A.; Pabon, M.; Trümper, M.; Berger, U.; Knapen, D.; Herzke, D. The structure of the fire fighting foam surfactant Forafac ${ }^{\circ} 157$ and its biological and photolytic transformation products. Chemosphere 2012, 89, 869-875.

[58] Munoz, G.; Desrosiers, M.; Duy, S. V.; Labadie, P.; Budzinski, H.; Liu, J.; Sauvé, S. Environmental Occurrence of Perfluoroalkyl Acids and Novel Fluorotelomer Surfactants in the Freshwater Fish Catostomus commersonii and Sediments Following Firefighting Foam Deployment at the Lac-Mégantic Railway Accident. Environ. Sci. Technol. 2017, 51, 1231-1240.

[59] Mejia-Avendaño, S.; Munoz, G.; Vo Duy, S.; Desrosiers, M.; Benoît, P.; Sauvé, S.; Liu, J. Novel Fluoroalkylated Surfactants in Soils Following Firefighting Foam Deployment During the Lac-Mégantic Railway Accident. Environ. Sci. Technol. 2017, 51, 8313-8323.

[60] Higgins, C. P.; Luthy, R. G. Modeling sorption of anionic surfactants onto sediment materials: an a priori approach for perfluoroalkyl surfactants and linear alkylbenzene sulfonates. Environ. Sci. Technol. 2007, 41, 3254-3261. 
[61] Labadie, P.; Chevreuil, M. Biogeochemical dynamics of perfluorinated alkyl acids and sulfonates in the River Seine (Paris, France) under contrasting hydrological conditions. Environ. Pollut. 2011, 159, 3634-3639.

[62] Chandramouli, B.; Benskin, J. P.; Hamilton, M. C.; Cosgrove, J. R. Sorption of per- and polyfluoroalkyl substances (PFASs) on filter media: Implications for phase partitioning studies. Environ. Toxicol. Chem. 2015, 34, 30-36.

[63] Guelfo, J. L.; Higgins, C. P. Subsurface transport potential of perfluoroalkyl acids at aqueous filmforming foam (AFFF)-impacted sites. Environ. Sci. Technol. 2013, 47, 4164-4171.

[64] Ahrens, L.; Yeung, L. W. Y.; Taniyasu, S.; Lam, P. K. S.; Yamashita, N. Partitioning of perfluorooctanoate (PFOA), perfluorooctane sulfonate (PFOS) and perfluorooctane sulfonamide (PFOSA) between water and sediment. Chemosphere 2011, 85, 731-737.

[65] Bowman, J. C.; Zhou, J. L.; Readman, J. W. Sediment-water interactions of natural oestrogens under estuarine conditions. Mar. Chem. 2002, 77, 263-276.

[66] Gibbs, R. J.; Tshudy, D. M.; Konwar, L.; Martin, J. Coagulation and transport of sediments in the Gironde Estuary. Sedimentology 1989, 36, 987-999.

[67] Turner, A.; Rawling, M. C. The behavior of di-(2-ethylhexyl) phthalate in estuaries. Mar. Chem. 2000, 68, 203-217.

[68] Droppo, I. G.; Ongley, E. D. Flocculation of suspended sediment in rivers of southeastern Canada. Water Res. 1994, 28, 1799-1809.

[69] Manning, A. J.; Langston, W. J.; Jonas, P. J. C. A review of sediment dynamics in the Severn Estuary: influence of flocculation. Mar. Pollut. Bull. 2010, 61, 37-51.

[70] Chen, H.; Zhang, C.; Yu, Y.; Han, J. Sorption of perfluorooctane sulfonate (PFOS) on marine sediments. Mar. Pollut. Bull. 2012, 64, 902-906.

[71] You, C.; Jia, C.; Pan, G. Effect of salinity and sediment characteristics on the sorption and desorption of perfluorooctane sulfonate at sediment-water interface. Environ. Pollut. 2010, 158, 13431347.

[72] Ahrens, L.; Bundschuh, M. Fate and effects of poly- and perfluoroalkyl substances in the aquatic environment: a review. Environ. Toxicol. Chem. 2014, 33, 1921-1929.

[73] Gao, Y.; Fu, J.; Meng, M.; Wang, Y.; Chen, B.; Jiang, G. Spatial distribution and fate of perfluoroalkyl substances in sediments from the Pearl River Estuary, South China. Mar. Pollut. Bull. 2015, 96, 226-234.

[74] Liu, S.; Lu, Y.; Xie, S.; Wang, T; Jones, K. C.; Sweetman, A. J. Exploring the fate, transport and risk of Perfluorooctane Sulfonate (PFOS) in a coastal region of China using a multimedia model. Environ. Int. 2015, 85, 15-26.

[75] Wang, T.; Vestergren, R.; Herzke, D.; Yu, J.; Cousins, I. T. Levels, Isomer Profiles, and Estimated Riverine Mass Discharges of Perfluoroalkyl Acids and Fluorinated Alternatives at the Mouths of Chinese Rivers. Environ. Sci. Technol. 2016, 50, 11584-11592.

[76] Chen, H.; Reinhard, M.; Nguyen, T. V.; You, L.; He, Y.; Gin, K. Y. H. Characterization of occurrence, sources and sinks of perfluoroalkyl and polyfluoroalkyl substances (PFASs) in a tropical urban catchment. Environ. Pollut. 2017, 227, 397-405. 
[77] Toublanc, F.; Brenon, I.; Coulombier, T.; Le Moine, O. Fortnightly tidal asymmetry inversions and perspectives on sediment dynamics in a macrotidal estuary (Charente, France). Cont. Shelf Res.

2015, 94, 42-54. 


\section{Tables and Figures}

Table 1. Partitioning behavior in the water column: water-suspended particle partitioning coefficients $\log K_{D}$ and $\log K_{o c}$ (mean $\pm S D$ ) ( $n_{m p}$ : number of matching pairs used in the calculation of the latter), particle-associated fraction $(\Phi, \%)$ (mean \pm SD and min-max), and estimates of freshwater partitioning $\left(K^{\circ}\right)$ and adsorption salting constants $(\delta$ and associated standard error $(\mathrm{SE}))$.

\begin{tabular}{|c|c|c|c|c|c|c|c|c|}
\hline & $\log K_{D}$ & $\log K_{o c}$ & $\mathrm{n}_{\mathrm{mp}}$ & $\begin{array}{l}\Phi \\
(\%\end{array}$ & & $\begin{array}{c}K^{\circ}{ }_{D} \\
\left(L^{\prime} k^{-1}\right)\end{array}$ & $\log K^{\circ}{ }_{D}$ & $\begin{array}{c}\delta(\operatorname{SE}(\delta)) \\
\left(\mathrm{L} \mathrm{mol}^{-1}\right)\end{array}$ \\
\hline PFBA & $2.5 \pm 0.3$ & $4.3 \pm 0.3$ & 3 & $23 \pm 6$ & $17-30$ & $\mathrm{NC}^{*}$ & - & NC \\
\hline PFPeA & $2.4 \pm 0.1$ & $4.2 \pm 0.2$ & 18 & $18 \pm 9$ & $4-33$ & $\mathrm{NS}^{* *}$ & - & NS \\
\hline PFHxA & $2.4 \pm 0.1$ & $4.2 \pm 0.2$ & 11 & $24 \pm 7$ & 14-34 & NS & - & NS \\
\hline PFHpA & $2.6 \pm 0.2$ & $4.5 \pm 0.3$ & 21 & $21 \pm 11$ & $6-44$ & 296 & 2.5 & $1.89(0.67)$ \\
\hline PFOA & $3.1 \pm 0.4$ & $5.0 \pm 0.5$ & 38 & $21 \pm 13$ & $4-53$ & 430 & 2.6 & $2.61(0.60)$ \\
\hline PFNA & $3.5 \pm 0.5$ & $5.4 \pm 0.5$ & 27 & $41 \pm 20$ & $14-82$ & 1737 & 3.2 & $1.79(0.47)$ \\
\hline PFDA & $3.7 \pm 0.1$ & $5.5 \pm 0.1$ & 7 & $80 \pm 14$ & $57-95$ & NC & - & NC \\
\hline PFUnDA*** & $3.8 \pm 0.1$ & $5.6 \pm 0.1$ & 12 & $74 \pm 17$ & $45-93$ & NS & - & NS \\
\hline PFBS & $1.3 \pm 0.2$ & $3.2 \pm 0.3$ & 5 & $1 \pm 1$ & $0.4-3$ & $\mathrm{NC}$ & - & $\mathrm{NC}$ \\
\hline PFHxS & $2.2 \pm 0.3$ & $4.1 \pm 0.3$ & 34 & $5 \pm 4$ & $0.9-17$ & 85 & 1.9 & $1.86(0.26)$ \\
\hline PFHpS & $2.6 \pm 0.3$ & $4.5 \pm 0.4$ & 16 & $21 \pm 11$ & $4-43$ & 308 & 2.5 & $2.21(0.43)$ \\
\hline Br-PFOS & $3.3 \pm 0.4$ & $5.2 \pm 0.5$ & 42 & $26 \pm 15$ & $9-58$ & 945 & 3.0 & $1.82(0.27)$ \\
\hline L-PFOS & $3.7 \pm 0.4$ & $5.6 \pm 0.5$ & 40 & $43 \pm 20$ & $15-82$ & 2169 & 3.3 & $1.84(0.22)$ \\
\hline FOSA $^{\star \star *}$ & $3.4 \pm 0.3$ & $5.3 \pm 0.3$ & 8 & $53 \pm 23$ & 20-88 & NS & - & NS \\
\hline 6:2 FTSA & $3.0 \pm 0.5$ & $4.9 \pm 0.5$ & 6 & $37 \pm 8$ & $23-45$ & $\mathrm{NC}$ & - & NC \\
\hline
\end{tabular}



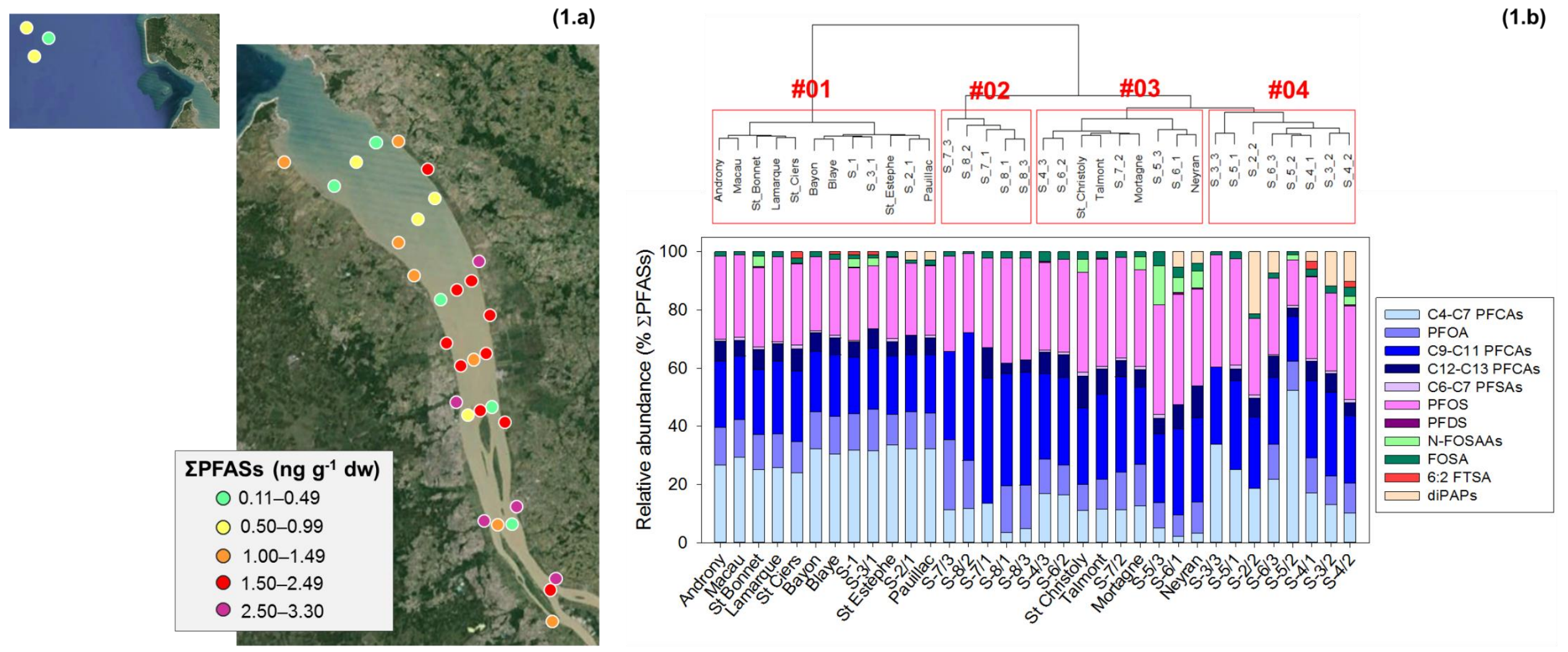

Figure 1. Spatial distribution of PFASs in sediments: cartographical mapping of PFAS sediment levels, color-coded according to $\sum$ PFASs (1.a), and PFAS abundance profiles in sediment samples, arranged through hierarchical clustering (Ward's method) (1.b). 

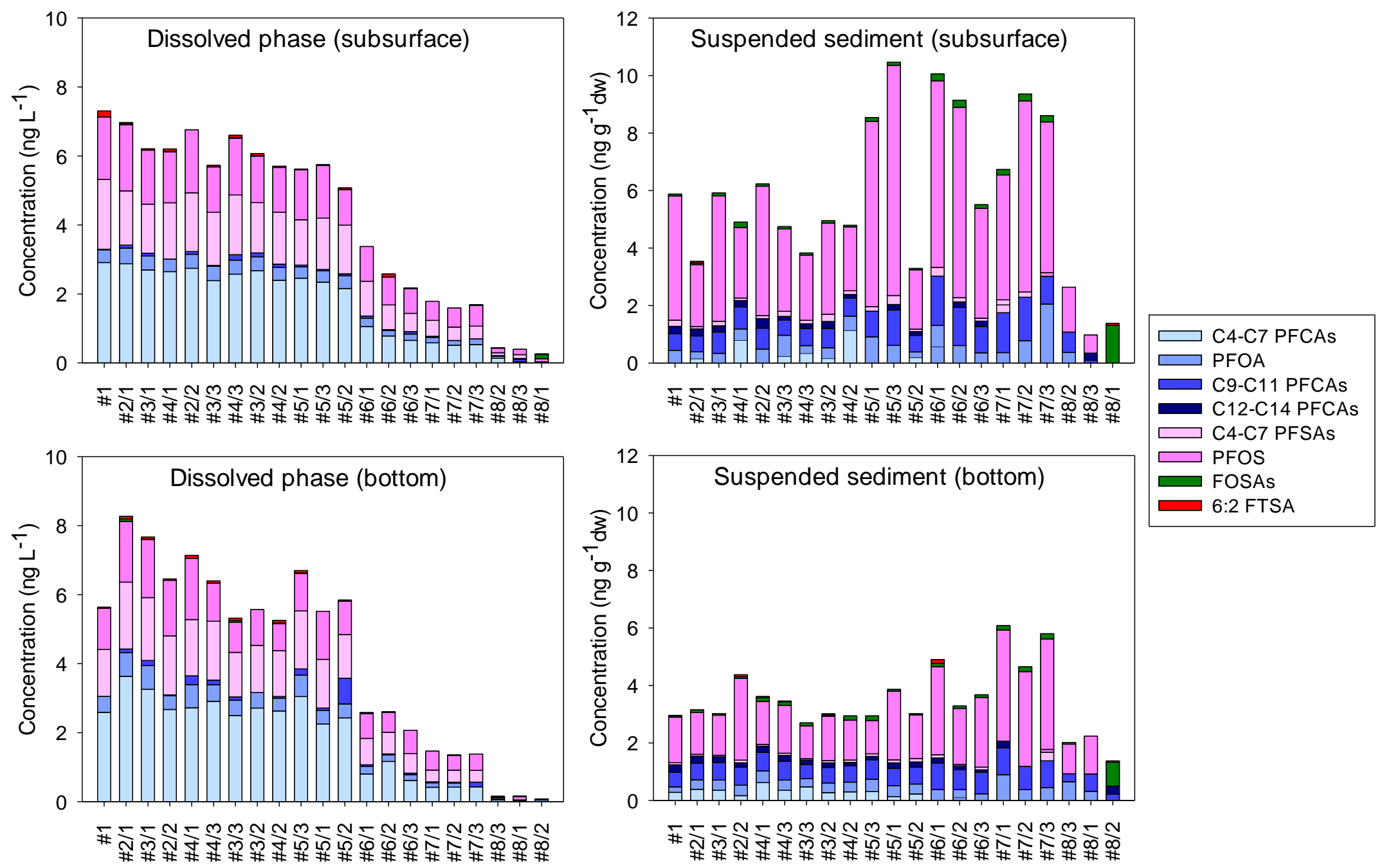

Figure 2. Concentrations and distribution of PFASs in the water column along the salinity gradient (arranged per increasing salinity). Salinity increases from site \#1 (Bec d'Ambès) to sites \#8 (offshore) (see also the SI for the location of sampling sites). 


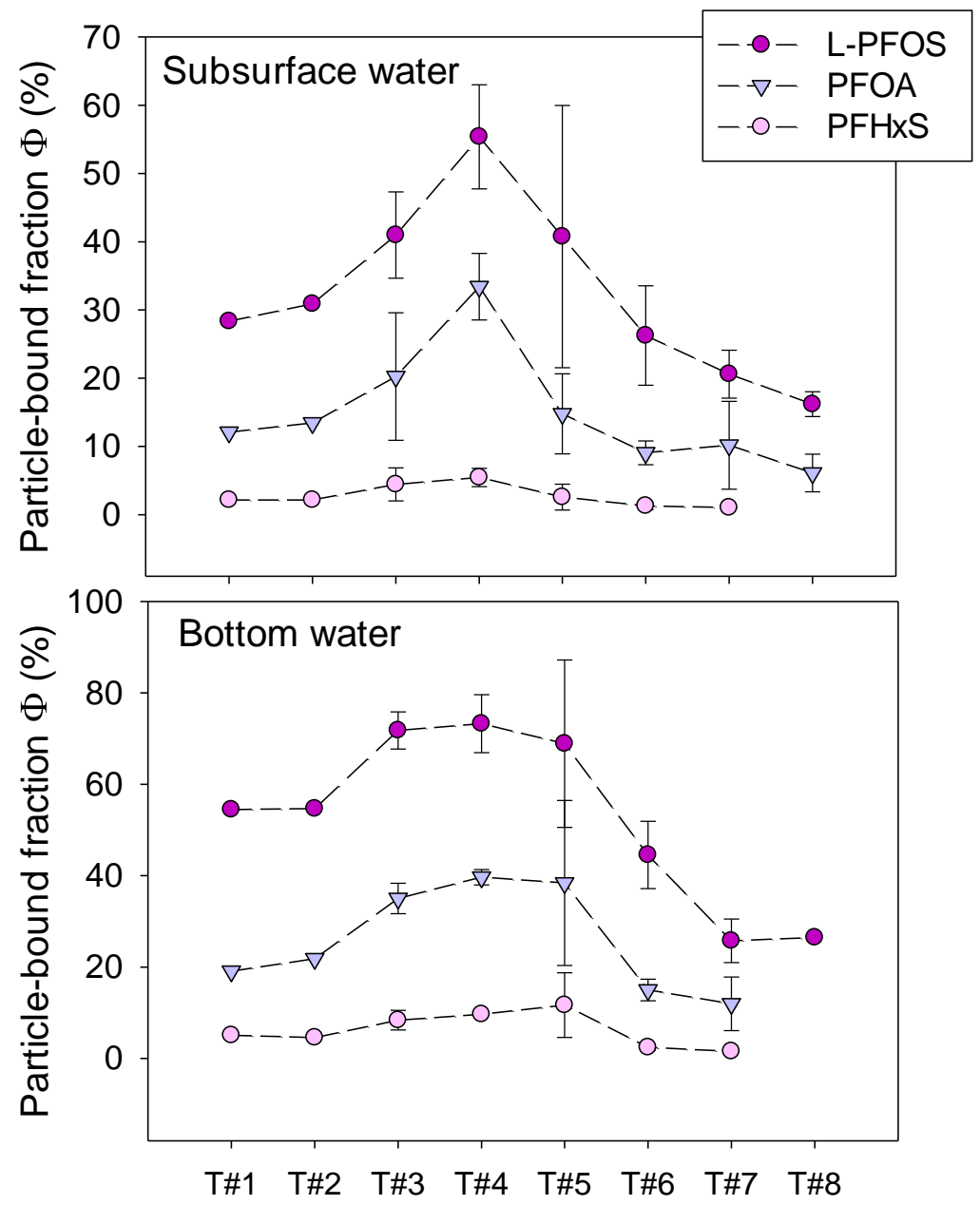

Figure 3. Evolution of the PFAS particle-associated fraction ( $\varphi, \%)\left(\mathrm{CSPM}_{\mathrm{SP}} / \mathrm{C}_{\text {water column}}\right)$ along transect zones T\#1 through T\#8 in subsurface and bottom water samples, illustrated for PFOA, PFHxS, and LPFOS (see the SI for location of sampling sites). Note the different scales for the $y$-axis. 

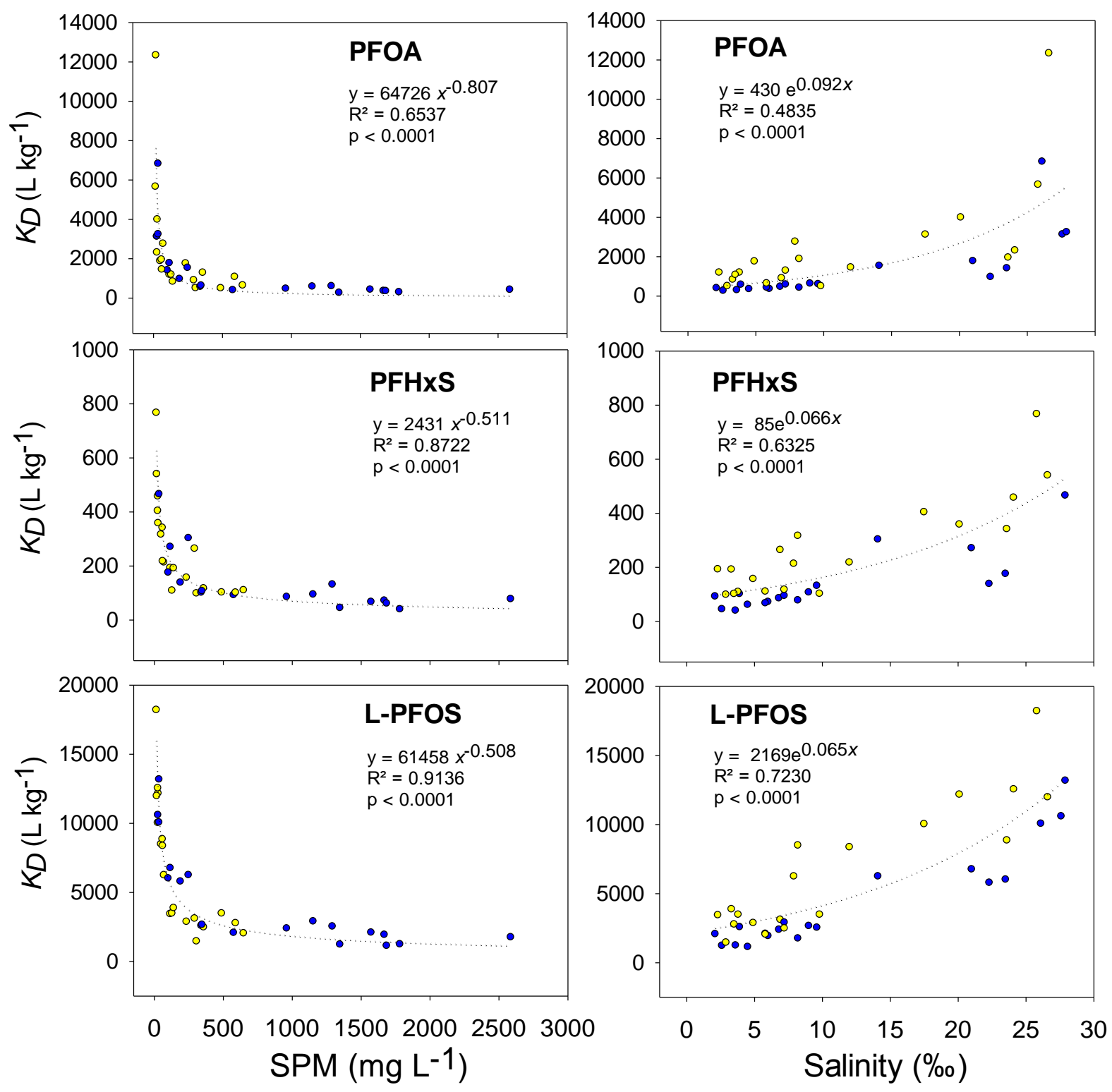

Figure 4. Influence of water quality parameters on the water-SPM partitioning coefficient $\left(K_{D}\right)\left(\mathrm{L} \mathrm{kg}^{-1}\right)$ illustrated for selected PFASs. Relationship $\left(R^{2}\right)$ between the suspended solid concentration in water (SPM, mg L-1) and $K_{D}$ (left), and between salinity (\%o) and $K_{D}$ (right). $K_{D}$ values are identified according to the position in the water column: subsurface (yellow) or bottom (blue) samples. 